\section{e-solutions in bioanalysis}

"I would challenge you to find an article published in Bioanalysis since its inception just a few years ago that did not have a computerized system of some sort as one of the enabling technologies at its core."

Keywords: computer $\approx$ data $\approx$ data acquisition $\approx$ electronic laboratory notebook $\approx$ electronic solutions ॥ ELN = laboratory information management system $=$ LIMS $\approx$ robotics

We wouldn't be where we are today without computers enabling many of the recent advances in society, much less our corner of the scientific world, bioanalysis. I would challenge you to find an article published in Bioanalysis since its inception just a few years ago that did not have a computerized system of some sort as one of the enabling technologies at its core. It seems that almost every conference or meeting on analytical chemistry includes at least one story of someone cutting and weighing chromatographic peaks back in the 'old days', but for the most part we have come to accept electronic data acquisition systems as standard. Even the HP Integrators that many of us used early in our careers had a computer chip at their core.

This edition of Bioanalysis is appropriately focused on electronic systems, or as the title states, 'e-solutions in bioanalysis'. There have been several important milestone moments in analytical and bioanalytical chemistry that relate directly to computerized e-solutions, but I do not know that a research journal such as Bioanalysis has ever focused specifically on the accomplishments of these contributors to our field. These milestones have included electronic instruments, integrators, data acquisition systems, robotics, laboratory information management systems (LIMS) and electronic laboratory notebooks (ELNs), to name some of the more prominent.

More and more I hear my colleagues around the world stating that they do not have the time or budgets to write, speak or sometimes even attend scientific meetings. I have been experiencing this personally. It is more difficult than ever to serve on planning committees for conferences when fewer and fewer scientists seem to be able to take the time like they used to. This edition of the journal even included several last minute regrets, "Sorry, I'm just too busy to write these days". The push to increase output, in our discipline that generally means sample throughput, is enormous. The answer to this challenge in many cases is with computerized systems or 'e-solutions' of one sort or another. This edition of Bioanalysis called on experts in e-solutions from a wide range of different areas such as paperless laboratories, compliance issues and laboratory robotics. We are fortunate that they have found the time, probably in evenings and weekends or from airplanes as I am doing now, to share their experiences with us.

With that, I won't take any more of your valuable time. I invite you to take a few moments from your day to read through this unique issue of Bioanalysis focused on e-solutions. I am confident you will find information in this edition that will help you increase the performance of your laboratory operation through computerized systems. Enjoy your reading, electronically I hope!

Financial \& competing interests disclosure The author has no relevant affliations or financial involvement with any organization or entity with a financial interest in or financial conflict with the subject matter or materials discussed in the manuscript. This includes employment, consultancies, honoraria, stock ownership or options, expert testimony, grants or patents received or pending, or royalties.

No writing assistance was utilized in the production of this manuscript.

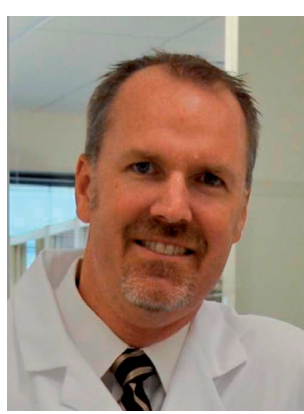

\section{Chad Briscoe}

North American Bioanalysis, PRA International, II070 Strang Line Road, Lenexa, KS 66221, USA Tel.: + + 9133455706 Fax: + I 9133455710 E-mail: briscoechad@praintl.com

\title{
FUTURE SCIENCE

